\title{
Difficulties in Assessing Pro-natalist Population Policy Programs
}

\author{
MIKKO A. SALO \\ University of Turku \\ Department of Economics and Social Policy
}

In 1960 a commission headed by Professor Richard M. Titmuss submitted a blueprint of social policy for the consideration of the government of Mauritius - then a self-governing British crown colony. The proposals which covered the whole field of social security, health and welfare were dominated by the explicit purpose of slowing down the excessive rate of population growth in the island (see Titmuss \& Abel-Smith 1968). Therefore, as was reported, the members of the commission hesitated whether or not to include a family allowance scheme among their suggestions. Their enquiries had shown that there were family needs which obviously could not be met without family assistance. On the other hand, however, they felt that the introduction of such measures could violate the objectives of their program by contributing to the persistence of high level fertility. The report made the following comment (ibid., p. 134):

»At an early stage in our work, we thus found ourselves torn between the aim of not giving any encouragement or even tacit approval in our recommendation to the rearing of large families and the evident fact that such families are at present the biggest single cause of poverty, malnutrition and family hardship.»

This hesitation may appear to us quite natural. The assumption that direct financial subsidies for families would provide an incentive for having more children seems not to contradict common sense. Family benefits are generally regarded as an instrument of pro-natalist policy in the industrialised countries (see Population Policy ... 1974, and Macura 1974). This is also the case with the developing countries which practise a policy deliberately designed to promote population growth (see Mouton 1975, 118).

The fact is, however, that the bulk of the studies in which the relationship between family benefits and fertility have been analyzed do not support the hypothesis of a positive impact. Or more conservatively, on the basis of demographic literature, it is reasonable to consider that the incidence of family benefits on the birth rate is open to question.

Recently, the concomitance of justifications of family assistance on demographic grounds and the lack of conclusive scientific evidence on the relationship between family policy measures and couples' fertility decisions has 
increasingly become a matter of actual discussion (see e.g. De Sandre 1978, Hohm 1976, and Mouton 1975, 115-122). Whether a government can exert any influence on the national fertility curve has been questioned. And it has been argued that »there is probably very little scope for resolute action» (see e.g. Calot \& Hecht 1978, 196, Berelson 1974, 788, Cavanaugh 1979).

The feasibility of recent approaches to these questions is discussed in this paper. Shortcomings and limitations in methods of evaluating the effects of pro-natalist policies practised in developed countries are highlighted. Difficulties in implementing assessment techniques adopted in evaluating social action programmes or measuring the effect of family planning programs on fertility are emphasized.

\section{On the impact of family benefits}

A U.N. review of the results of population research achieved by the early 1970 's presented, inter alia, a summary of studies on the impact of measures affecting fertility (see U.N. 1973, Chapter XVII). According to it »there do not appear to have been any studies that have established conclusively the relationship between fertility and the various measures that Governments have implemented which may conceivably influence it» (ibid. p. 644).

More recently, Gérald Calot and Jacqueline Hecht (1978), Brian F. Pendleton (1978) and Ann-Sofie Kälvemark have attempted to analyse family policy measures affecting fertility in some European countries.

(i) Gérald Calot and Jacqueline Hecht (1978) have discussed the effects of social policy favouring families in some European countries. They have concluded that the evidence available does not support the contention that a government can exert any very substantial influence on long-term fertility trends. For example, according to their estimate, the effect of French legislation - which has been extraordinarily favorable to families for the past 50 years - on fertility may have been at most around 10 per cent or 0.2 children per woman. This is, however, a rough and controversial estimate, using statistics which show that the high point of life-time fertility trends reached by the cohorts born around 1930 was only slightly higher in France (i.e., 2.6 children per woman) than in England or Germany (i.e., 2.4 and 2.2 children per woman, respectively).

(ii) Pendleton (1978) examined the pro-natalist policy enacted in Germany, Italy and Sweden between World War I and World War II in order to test hypotheses concerning the differences in efficiency of "coercive» and "noncoercive" forms of governmental interventions. He asked whether those countries that practise wcoercive" policies can expect either no effect on the country's birth rate or even a decline as a manifestation of people's negative reaction to coercion. Correspondingly, he hypothesised that a country of "non- 
coercive" pro-natalist techniques can expect a favorable reaction by the population, and as a result an increase in the birth rate.

However, the data he utilized did not suggest that "non-coercive» policies would have a pro-natalist impact on fertility. In the case of Sweden no such changes in the trends of fertility following the policy enactment in 1937 which could justify the conclusion of the influence of a favorable public reaction were observed.

Furthermore, the hypothesis that the countries of "coercive» pro-natalist policy techniques, e.g., Germany and Italy, would expect no effect or even a decline in their birth rate, was only partially supported. There was, in fact, an upsurge in the German birth rate from a low level of 14.7 per thousand in 1933 to a peak of 20.4 per thousand in 1939. Pendleton concluded that this rise was due to the scoercive» measures enacted by the German government in the 1930s. Simultaneously, however, the techniques of a similar character applied in Italy, apparently had no impact on its birth rate. And finally, despite the governmental attempts to stimulate the birth rate in Italy and Germany, it never reached the level regularly experienced in the early 1920 s.

(iii) In the study by Pendleton as well as, in the analyses by Calot and Hecht, family policy was treated as a whole. Ann-Sofie Kälvemark (1978), in turn, attempted to evaluate the demographic effects of a single measure - the Swedish marriage loans of the 1930s.

The scheme of marriage loans was designed to enable young couples to buy equipment necessary for their future homes. It was assumed that this would facilitate marriage at younger ages and, consequently, induce higher birth rates via the extended period within marriage. For entitlement to such a loan, the claimants were to be of small means, »known as steady and economically prudent», and if possible to have sshown willingness to save».

The proportion of the marriages which acquired marriage loans varied yearly from 12 to 21 per cent during the period 1938 to 1948 . Nevertheless, no sign of increased fertility was found by Kälvemark among the couples who were assisted in this way by the government. On the contrary, the marriage loan cohort's fertility appeared to be lower than the average. As a pro-natalist policy measure, Swedish marriage loans were, according to Kälvemark's judgment, a failure. "The fertility of families in a modern society is obviously not too easily affected", she concluded.

(iv) Still bearing in mind the dilemma which the Titmuss commission faced, let us finally look at an international analysis of the effects of family allowances by Charles F. Hohm (1976). By employing regression analysis techniques on data from 67 countries in the 1960 s, he found an inverse association between fertility and family allowance programs as indicated by the coverage and benefit level.

The coverage referred to the number of children in a country who were family allowance recipients relative to the total number of young persons under the age of 15 . A benefit level index was constructed to indicate the rel- 
ative importance of family allowance payments among the sources of family income in a country. As such the average annual payment made with respect to a child divided by the average annual wage of employees in manufacturing was utilized.

The preliminary findings of a non-existent association between family allowance indices and fertility lead Hohm to hypothesize that these associations probably were spurious due to the uncontrolled variation in national economic wellbeing. However, an independent association between coverage index and the total fertility rate appeared to be significantly inverse, if the level of economic development indicated by per capita gross domestic product in terms of the economically active population was also held constant.

In this way Hohm came up against the question of causal order. Why would the independent effect of the coverage index on fertility be inverse, he asked. A feasible explanation, as he suggested, was that it would be possible to reverse the causal order, treating fertility as the independent variable and family allowance as the dependent one. Obviously, the lower the level of fertility in a country the less expensive and difficult it is to introduce a family allowance scheme extensively covering the child population. Correspondingly, the higher the level of fertility the greater the relative number of dependent children and the greater the difficulties to finance and establish an effective family allowance program.

Hohm concluded that the evidence strongly supported the hypothesis that the improvements of family allowance systems have not resulted in increases in fertility. He wrote (ibid., p. 55):

- Therefore, if a country desires to implement or expand family allowance programs in order to raise the living standard of its children, the data in this study suggests that such an implementation of expansion can be done without fear of raising the fertility level.»

Thus, Hohm seems to give an outspoken answer to the question which, as mentioned above, made the members of Titmuss Commission so anxious. To sum up, the studies reviewed here failed to show that the government via the institutions of family policy can exert a substantial influence on national fertility. This seems to be the case whenever the effectiveness of particular measures are questioned, as well as when the results of a complex policy combined to a mixture of different activities are assessed.

\section{The under-developed evaluation studies}

One may feel tempted to take a pragmatic stand by insisting that the studies so far considered only demonstrate the insufficiency of these measures with respect to their coverage and benefit levels. The concurrent social policies frequently have inconsistent goals or contradictory side-effects; some of them are expected to have pro-natalist influences, while others may be, in fact, antinatalist. According to this reasoning, the payments ought to be considerably 
higher in order to conquer the opposing effects which tend to lower the birth rates.

It seems, however, unjustified to ask for more resources to be allocated to the family allowance scheme without any prediction about where the critical upper limit of the benefits would be - and more significantly - without knowing if there is any. Obviously, more accurate information about the relationships between social policies and fertility behavior is needed.

Several apparent difficulties and limitations are involved in the studies reported up to now. In the first place, there is a serious lack of systematically collected and well-organized data for family-life variables in different social classes and economic sections of the population. This is particularly true in the case of families which were in the midst of their fertile period some decades ago, as demonstrated in the Pendleton's study.

Secondly, the improper use of the crude birth rate as the dependent variable has not always been avoided. For example, the limitations which resulted from his choice to utilize the birth rate instead of some more sophisticated fertility indicators as the dependent variable in his study, was not discussed by Pendleton. Calot and Hecht, in contrast, cautioned even against the conclusions drawn from the period fertility index (i.e. the total fertility rate). They strongly recommended the life-time fertility index as being, among the yardsticks of fertility, sthe only proper one for assessing changes in the intensity of procreative behaviour» (Calot \& Hecht 1978, 180). Unfortunately, the establishment of life-time fertility trends for successive cohorts is not always feasible for obvious reasons.

The assessment of policy performance is further complicated by the problems of predicting the development in the absence of a demographic policy. Without predictions concerning the level of fertility which would be achieved if no action had been taken, no quantified estimation of the policy impact is, of course, feasible.

The criterion utilized by Kälvemark was the fertility of Swedish marriage cohorts in general during the period the marriage loan scheme was in force. Since her interest was focused on the effectiveness of a single policy measure, choosing the point of comparison was less complicated for her, in contrast to the studies by Pendleton or Calot and Hecht.

Pendleton, however, appeared fairly contented in his attempt to find simply such stops or changes in the downward trends of the birth rate which, with regard to their temporal sequence, could be attributed to the enactment of specific policy measures. He wrote (op. cit., 61):

"Such »eyeballing» of the data as we have done is an extremely simple method for interpreting the effects of pro-natalist policies. The social context is not, and perhaps cannot be, defined accurately or quantitatively. But, an intrinsic understanding of pro-natalist policies and their relative placement on the graphed birth rate is important and worthwhile.» 
Calot and Hecht were only slightly more accurate: They admitted that it would be "very hazardous» to try to quantify the effect of legislation on family policy. However, they applied a method of comparing the life-time fertility indeces of corresponding cohorts in the neighboring countries. For example, they found that the life-time fertility of cohorts born around 1930 was 2.6 in France, 2.4 in England and Wales, and 2.2 in the Federal Republic of Germany and Belgium. These findings led them to estimate that the effect of French legislation has been in the region of 0.2 children per woman.

As noted by Calot and Hecht this result is obtained only by supposing that the differences in fertility between these countries were totally due to the differences in their family policies. Then, in fact, an unspecified number of factors must be assumed to be controlled or to have no intervening effect.

The attempts at quantification and cross-cultural comparisons are the most essential features of the study by $\mathrm{Hohm}$. The data he analyzed covered 67 countries. It was his study design to fit regression equations to this numerical data in order to describe the relationship between fertility and family allowance in terms of multiple regression and correlation coefficients. In other words, the equations approximately should show how much fertility changes in relation to changes in family allowances if the values of a few control variables were known. For the planner searching for policy guidelines in a country with a low birth rate, this would be beyond all expectations: by utilizing Hohm's equations he would be able to calculate in a quite simple manner, for example, how large increases in family allowance payments were needed in order to achieve the fertility level considered as more suitable, and then estimate how much this reform would cost with regard to the resources available. Urfortunately, it was only a dream.

Firstly, no association between fertility and family benefit level was found by Hohm. The only statistically significant Beta coefficient was the one of the coverage index. While being negative it indicated, as mentioned above, that the relationship between the coverage of a family allowance scheme and fertility was inverse which means that in order to increase the level of fertility one ought to reduce the number of benefit recipients - not to expand it!

The explanation of this dilemma offered by Hohm displays the fundamental problems of causality involved in multiple regressions. As mentioned above, Hohm suggested the reversed causal order: the level of fertility should be treated as the independent variable and the coverage index as the dependent one. Thus, the regression analysis did not directly give any answer to the question of which one of the two interrelated traits is the cause.

From the point of view of the planner, obviously, the idea of the reversed causal order is disappointing as well, because it provides no clues as to the proper measures for pro-natalist policy.

There still are some other problems generally inherent in the approach of multiple regression: Hohm's study is typically ahistorical. No differences in developmental trends, which led to the situation prevailing in particular 
countries in the beginning of $1960 \mathrm{~s}$, were taken into account. Without any explicit theory which could be used to guide the selection process of control variables, the final combination of factors included is arbitrary. Important variables probably have been excluded simply because the data were not available. Thus, as recently argued by Ruth B. Dixon (1978), the use of regression analysis in formulating population policies can be highly misleading.

The difficulties in making causal inferences from correlations in the crosscultural survey is widely known among social scientists (see e.g., Smelser 1976). As it was stated by Raoul Naroll $(1971,244)$ :

... if we find that two traits (i.e. variables) are correlated, and if we have some reason to believe that one is the cause and the other the effect, our concern about sampling bias, unit definition inconsistency, Galton's problem, data quality, or even concept definition, is simply a concern that the observed correlation is an artifact of one or more of these five elements of our research method.»

By Galton's problem is meant that of discriminating the »historical» associations from the »functional» ones (see e.g., Naroll 1961). In other words, the question is how do we know that, say, the decline of fertility emerging with the expansion of population policy in a sample of countries really is due to some functional association - and does not simply reflect changes in political and fertility behavior spread by diffusion via mass media, borrowing or migra-. tion from one country to another. ${ }^{1}$ A few solutions to Galton's problem have been offered - none of them being very practical here (see Naroll 1971).

Paolo de Sandre (1978) hit it right when he argued that only the legislator »assumes that legislation can influence demographic variables directly, and this assumption has not been put to the test in appropriate practical terms» (ibid., p. 150). By and large, it is always difficult to distinguish whether the subsequent behavioral modifications are due to the introduction of the new law, or whether they are a result of more general pressures of an economic and social nature which gave rise to the law itself. Apparently such interpretative assumptions which cannot be scientifically checked are frequently made at the present phase of knowledge on pro-natalist policies.

\section{The developed evaluation studies}

de Sandre (ibid.) emphasized that more sophisticated techniques of analysing the effects of pro-natalist policy measures are needed. It is also known that evaluation research methods have been developed in two neighboring sectors of the social sciences; viz., the methods of evaluating the effectiveness of social programs and the techniques of measuring the impact of family planning programs on fertility in the Third World. If the assessment methodology of

1 For an analysis of the influence of mass media on fertility see Freedman (1976). 
pro-natalist family policy is still in the elementary state, what can the planner learn from these studies?

Various approaches to the problems of evaluating social policies have been advanced since the early 1960's. According to Peter H. Rossi (1972) it is, however, feasible to group them under two general headings:

On the one hand, there is the school of policy analysis characterized by systemic attempts to find solutions to the dilemmas of informed and intelligent decision making in the political process. As defined by Yehezkel Dror $(1971,55)$ the aim of policy analysis is »to provide a heuristic method for identification of preferable policy alternatives». This is the problem area to which the economists were inclined to address themselves and where the methodology of the cost-benefit analysis is cultivated (see Mishan 1972 and Irvin 1978).

On the other hand, there have been simultaneous efforts to determine the effectiveness of particular social programs already realized by the government. An increasing number of behavioral social scientists have been concerned with the extent to which the policies seemed to have accomplish intended effects (see Alberts 1970, Rossi 1972, Cain \& Hollister 1972, Weiss 1972, Bell 1975, Elkin \& Vorwaller 1975, Swart et al. 1976, Tydeman \& Mitchell 1978). Their basic methodological model, as opposed to economic cost-benefit calculations, was mainly the controlled experiment and its derivations (see e.g., Fairweather \& Tornatzky 1977).

The work by Blumstein and Cassidy (1973, see also Robinson 1975) can be utilized here to demonstrate a fundamental problem of cost-benefit analysis if applied in the area of population policy. They presented a stochastic model designed to estimate sthe expected social costs with and without a family planning program provided to a population» (ibid., 151). According to their reasoning, three kinds of information are needed in order to make rational choices between different policy options. These are estimations of the costs of unwanted births, the costs of alternative programs and their efficacy in preventing unwanted births. With these estimates, as they stated, »we are in a position to compare the value of high efficacy, high cost programs against lower-efficacy-lower-cost programs against no program at all.»

Obviously, the most substantial difficulty is to obtain reliable information about the efficacy of alternative programs. The measurements available, if any, are scarcely generally applicable due to differences between cultures and societies. And, in fact, measuring the demographic impact of specific family planning programs is clearly beyond the scope of cost-benefit analysis.

Family planning program evaluation is »a process that includes measurement of goal achievement, feedback of information for adaptive decisionmaking, and examination of a wide variety of processes to determine why a program was or was not successful» (Reynolds 1972, 69). According to Mauldin and Jonson-Acsádi (1975) there are several complicated subtasks involved: 
Firstly, the determinants of fertility and the processes of demographic transition ought to be well understood to enable the evaluator to predict what the secular trend of fertility would have been in the absence of the program. Without knowing the simultaneously occurring significant socio-economic and cultural changes in the society, it is not possible to estimate the net impact of the program. Furthermore, there is the question of whether a new trend in fertility really was initiated by the program or whether already existing trends only were expedited.

Secondly, there may be modifications in values and behavior outside the circle of couples who have been directly contacted by the program. There may even occur such favorable changes which were not discovered among the directly "persuaded" people. To determine the full impact of the program, techniques for measuring both the indirect and direct effects are needed.

Thirdly, the couples directly covered by the program may constitute an unrepresentative subsample of all couples in the population, e.g. with respect to parity, motivation to limit childbearing, or the experience of contraceptive practice. Therefore comparisons between the observed and potential fertility are necessary.

Finally, a distinction must be made between the short-term and long-term effects of the program. Mostly the programs aim to effect changes in the completed family size or life-time fertility trend of entire cohorts. In many cases, however, it is only possible to observe the short-term effects, e.g., changes in the distributions of birth intervals. The problem, then, is to what extent an assessment can be made while the women under study still are subject to the risk of child-bearing.

To sum up, we feel that the methodology of cost-benefit analysis cannot provide any first-aid to the planner confronting the task of evaluating pronatalist policies. Nevertheless, becoming familiar with the process of measuring the effect of family planning programs on fertility would be much more beneficial as far as the complicated methodological problems mentioned above can be considered as being solved satisfactorily by now (c.f. Chandrasekaran \& Hermalin 1975, Nortman et al. 1978). There are, however, substantial differences between pro-natalist policies in developing countries and the population policy designed to reduce fertility in the Third World. To realize it, an acquaintance with the experiences achieved in the evaluation research of social programs in the Western World be useful.

In the first place, the demographic goals of family policy measures in the developed countries are usually not explicitly defined (see Berelson 1974). For example, family assistance schemes are normally justified on social welfare grounds while their demographic intent is more latent. Then two consequences are inevitable: On the one hand, the more vaguely phrased the objectives of a program, the more difficult it is to select the most effective measures. As expressed by Rossi $(1972,18)$, »it is hard enough to change individuals, but it is even harder to change individuals to an unspecified state.» On the other 
hand, it is impossible to assess accurately to what extent the program has accomplished its intended effects if the goals are ambiguously defined.

Apparently, in many developed countries, a highly elaborate social welfare apparatus has been developed without a goals-effects-evaluation tradition. In these countries the decision-making process is controlled rather by political aspects associated with alternative programs than by their tested efficacy in achieving the goals intended (see Bell 1975, 156-161).

Such being the case, those who are involved in the matter, are, probably, not primarily concerned with quantifying the effects of the program:

»By and large, the interest is in finding positive effects and not negative effects or no effects at all. Those who have proposed programs do so with the conviction that the programs are effective; those who administer the programs have an interest in showing that under their leadership the programs have accomplished something; and evaluators who are connected more or less intimately with the programs are not likely to want to offend by showing that programs do not work.» (Rossi 1972, 22).

Although these observations by Rossi (1972) were made in the context of evaluating social programs in general, they certainly are illustrative as far as specific pro-natalist family policies are concerned, as well.

\section{Summary and concluding comments}

Family policy has recently attained actuality as a matter of debate. In this paper, the attempts at evaluating the demographic effects of family assistance were examined. A review of some recent studies to assess the effect of family benefits on fertility was used to introduce a discussion of a few methodological issues. The difficulty in including relevant variables into the analysis, the problems of predicting demographic development in the absence of governmental interventions, the limitations of cross-cultural comparisons were highlighted.

It seems to us that the approaches employed in studies to assess the demographic effects of pro-natalist family policy are in a state of under-development. However, experiences of evaluation research in the field of neighboring disciplines have not been sufficiently utilized by now. It appears reasonable to assume that becoming familiar with the extensive literature about assessing social programs or measuring the effect of family planning programs in the Third World would be beneficial. Although no revolutionary contribution is to be expected, it certainly could provide a more comprehensive frame of analysis. Not only the determinants of fertility and the laws of parental behavior - but also the processes of decision-making in social policy - could then be better understood. 


\section{References}

Alberts, David, S. 1970: A Plan for Measuring the Performance of Social Programs. Praeger, New York.

Bell, Robert 1975: Att utvärdera sociala program. Wahlström \& Widstrand, Stockholm. Berelson, Bernard 1974: Summary. In Berelson, B. (ed.): Population Policy in Developed Countries. MacGraw-Hill, New York, p. 771-789.

Blumstein, A. and R. G. Cassidy 1973: Benefit-cost analysis of family planning. SocioEconomic Planning Sciences 7, 151-160.

Cain, Glein, G. and Robinson G. Hollister 1972: The methodology of evaluating social action programs. In Rossi, Peter H. and Walter Williams (eds.): Evaluating Social Programs. Seminar Press, New York, p. 110-139.

Calot, Gerard and Jacqueline Hecht 1978: The control of fertility trends. In Population Decline in Europe. Council of Europe, London, p. 178-197.

Dixon, Ruth B. 1978: On drawing policy conclusions from multiple regressions: Some queries and dilemmas. Studies in Family Planning 9, 286-288.

Cavanaugh, J. A. 1979: Is fertility declining in the less developed countries? Population Studies 32, 283-295.

Chandrasekaran and Albert I Hermalin (eds.) 1975: Measuring the Effect of Family Planning Programs on Fertility. Ordina Editions, Dolhain.

Dror, Yehezkel 1971: Design for Policy Sciences. Elsevier New York.

Elkin, Robert and Darrel J. Vorwaller 1975: Evaluating the effectiveness of social services. In Lee J. Seidler and Lynn L. Seidler (eds.): Social Accounting. Melville, Los Angeles, p. 410-425.

Fairweather, George W. and Louis G. Tornatzky 1977: Experimental Methods for Social Policy Research. Pergamon Press, Oxford.

Freedman, Deborah S. 1976: Mass media and modern consumer goods: Their suitability for policy interventions to decrease fertility. In Ronald G. Ridker (ed.): Population and Development. John Hopkins Univ. Press, Baltimore, p. 356-386.

Hohm, C. F. 1976: An international analysis of the effects of family allowance program on fertility levels. International Journal of Sociology of Family 6, 45-56.

Irvin, George 1978: Modern Cost-Benefit Methods. The Macmillan Press, London.

Kälvemark, Ann-Sofie 1978: Swedish marriage-loans - A means of increasing population? In Åkerman, Sune, Hans Christian Johansen and David Gaunt (eds.): Chance and Change. Odense Univ. Press, p. 244-258.

Macura, Milos 1974: Population policies in socialist countries of Europe. Population Studies 28, 369-378.

Mauldin, W. Parker and Gwendolyn Johnson-Acsádi 1975: Introduction. In Chandrasekaran C. and Albert I Hermalin (eds.): Measuring the Effect of Family Planning Programs on Fertility. Ordina Editions, Dolhain, p. $1-15$.

Mishan, E. J. 1972: Elements of Cost-Benefit Analysis. George Allen and Unwin, London. Mouton, Pierre 1975: Social Security in Africa. ILO Geneva.

Naroll, Raoul 1961: Two solutions to Galton's problem. Philosophy of Science 28, 15-39.

Naroll, Raoul 1971: Some thoughts on comparative method in cultural anthropoligy. In Blaloc, Hubert M. and Ann B. Blalock (eds.): Methodology in Social Research. McGraw-Hill, London, p. 236-277.

Nortman, Dorothy, L., Robert G. Potter, Sharon W. Kirneyer, John Bongaarts 1978: Birth Rates and Birth Control Practice. The Population Council, New York.

Pendleton, Brian, F. 1978: An historical description and analysis of pronatalist policies in Italy, Germany, and Sweden. Policy Science 9, 45-70.

Population Policy in Developed Countries. Ed. by Bernard Berelson. McGraw-Hill, New York 1974. 
Reynolds, J. 1972: Evaluation of family planning program performance: A critical review. Demography 9, 69-86.

Robinson, W. C. 1975: The methodology of cost-benefit analysis of expenditures on population control programmes. In U.N.: The Population Debate: Dimensions and Perspectives: Papers of the World Population Conference, Bucharest, 1974. Vol 2. p. $550-559$.

Rossi, Peter H. 1972: Testing for success and failure in social action. Rossi, Peter, H. and Walter Williams (eds.): Evaluating Social Programs. Seminar Press, New York, p. $11-49$.

Sandre, Paolo de 1978: The influence of governments. In Population Decline in Europe. Council of Europe, London p. 145-170.

Smelser, Neil, J. 1976: Comparative Methods in Social Sciences. Prentice-Hall, Englewood-Cliffs, N. J.

Swart, William w., Irvin Kruger, Harry Burgess and Daniel Rubinstein 1976: A system for evaluating social welfare programs and allocating contributing resources based on citizen input. Socio-Economic Planning Sciences 10, 107-116.

Titmuss, R. M. and B. Abel-Smith 1968: Social Policies and Population Growth in Mauritius. Frank Cass, London.

Tydeman, John and Robert Mitchell 1978: Policy evaluation under uncertainty: An approach using subjective information Socio-Economic Planning Sciences 12, 227284.

U.N. 1973: The Determinants and Consequences of Population Trends. Vol 1 .

Weiss, Carol H. 1972: Evaluation Research. Prentice-Hall, Englewood-Cliffs, N.J. 